\title{
Study of Oral Isotretinoin (13-Cis-Retinoic Acid) Therapy in Patients of Acne Vulgaris
}

\author{
Sankalp Awasthi ${ }^{*}$, Nek Ram Baghel ${ }^{2}$, Sweta Kumari ${ }^{3}$, Pankaj Rao ${ }^{4}$, Saurabh Agrawal ${ }^{5}$, R S Rajpoot ${ }^{6}$ \\ ${ }^{1}$ Assistant Professor, ${ }^{2}$ Associate Professor \& Head, ${ }^{3}$ Lecturer, Department of Dermatology, \\ ${ }^{6}$ Additional Professor, Department of Physiology, \\ Uttar Pradesh University of Medical Sciences, Saifai, Etawah, UP, India. \\ ${ }^{4}$ Assistant Professor, Department of Dermatology, Dr. SN Medical College, Jodhpur, Rajasthan, India. \\ ${ }^{5}$ Consultant Dermatologist, Kothari Medical and Research Institute, Bikaner, Rajasthan, India.
}

\section{ABSTRACT}

Objectives: Present study was conducted to determine efficacy and safety profile of oral isotretinoin (13-Cis-Retinoic Acid) therapy in patients of acne vulgaris.

Methodology: Present study was carried out among the acne vulgaris cases attending the outpatient department of dermatology, Uttar Pradesh University of Medical Sciences, Saifai, Etawah, UP (India) during April 2015 to March 2016. 56 patients with grade II to grade IV acne vulgaris as per Pillsbury's scale, within the age group of 14-25 years were included for study. In all these cases a general and cutaneous examination was carried out and type and distribution and count of acne lesions comedons, inflammatory lesions as well as total lesions were recorded. The lesions were counted by using Leeds technique of Burke and Cunliffe. Oral isotretinoin was started at a dose of $0.5 \mathrm{mg} / \mathrm{kg} /$ day for a total duration of 20 weeks. Patients were scheduled for 3 visits i.e. at the end of 1st, 2nd \& 5th month after start of treatment. Efficacy was determined by evaluating inflammatory lesions count at baseline and at every visit. A safety evaluation was carried out for cutaneous and mucosal, hair and nail changes and any systemic side effects at each schedule visit.

Results: Comedons decreases from baseline 39.19 to 10.15 at the time of last visit i.e. on 5 th month. As well as inflammatory lesions decreased from 32.85 to 5.35 at the time of last visit at 5 month. These findings were statistically significant $(<0.001)$. Safety evaluation of the drug was observed with the side effect

\section{INTRODUCTION}

Acne vulgaris is a chronic inflammatory disease of pilosebaceous units, characterized by comedones, papules, pustules, nodules, cysts, abscesses and later on sometimes as widespread scarring. ${ }^{1}$ Acne is distributed mainly over the face, upper back, chest and upper arms. This disease occurs worldwide and usually starts in adolescence and resolves by the midtwenties. ${ }^{2}$

The origin of acne vulgaris is complex and incompletely understood. At least 4 pathophysiologic events take place within acne-infected hair follicles: (1) androgen-mediated stimulation of sebaceous gland activity, (2) abnormal keratinization leading to follicular plugging (comedo formation), (3) proliferation of the of the drug during or at the end of the treatment. Dry skin, Dry mouth, Dry eyes, palmo-plantar peeling, exfoliative dermatitis, photosensitivity, facial dermatitis, skin infections, \& Cheilitis were observed. Systematic side effects like Nausea, diarrhea, abdominal pain were observed in 2 patients.

Conclusion: It can be concluded that oral isotretinoin is an effective and safe drug in the management of acne producing long-term remission and/or significant improvement in many patients.

Keywords: Acne Vulgaris, Adverse effects, Oral Isotretinoin, Efficacy.

\section{*Correspondence to:}

Dr Sankalp Awasthi,

Assistant Professor, Department of Dermatology, Uttar Pradesh University of Medical Sciences, Saifai, Etawah, UP, India.

Article History:

Received: 13-06-2016, Revised: 08-07-2016, Accepted: 22-07-2016

\begin{tabular}{|l|c|}
\hline \multicolumn{2}{|c|}{ Access this article online } \\
\hline Website: & Quick Response code \\
www.jjmrp.com & \\
\hline DOI: & \\
10.21276/jmrp.2016.2.4.036 & \\
\hline
\end{tabular}

bacterium Propionibacterium acnes within the follicle, and (4) inflammation. In addition to these 4 basic mechanisms, genetic factors, stress, and possibly diet may influence the development and severity of acne..$^{3-6}$ According to the severity of acne, there are various treatment modalities available. They include both topical and systemic therapy. Effective treatment is essential to prevent physical and psychological scarring. So it's essential to target the inflammatory lesions. Antibiotics continue to play an integral role in the management of acne. Systemic treatment is required in patients with moderate to severe acne, especially when acne scars start to occur. ${ }^{7-9}$ 
The introduction of isotretinoin for acne was a major therapeutic advancement which revolutionized the treatment of acne. Isotretinoin is the only treatment that has an effect on the entire major etiological factors involved in acne i.e. decrease sebum production, comedogenesis, surface and ductal colonization of $P$. acne, anti-inflammatory. Isotretinoin (13-cis retinoic acid) represents the single most important advance in acne therapeutics. ${ }^{10}$

Vitamin A is essential for proper differentiation of epithelia, including those lining the hair follicles and the sebaceous glands. Although the follicular keratinization is disturbed both in vitamin A deficiency and in acne vulgaris. The importance of hypovitaminosis $A$ in the pathogenesis of acne is still highly controversial. Recently the serum concentrations of retinol and retinol-binding protein (RBP) and the skin concentrations of retinol were found to be somewhat lower in acne patients than in healthy controls. ${ }^{11-14}$

Isotretinoin is given in a dosage of 0.5 to $1.0 \mathrm{mg} / \mathrm{kg} /$ day after meals in severe nodulocystic acne and the treatment is continued till a cumulative dose of $120-150 \mathrm{mg} / \mathrm{kg}$ has been achieved. This causes many dose-dependent mucocutaneous and systemic sideeffects.

To overcome this limitation lower doses of isotretinoin are being tried. Lower doses of isotretinoin may be effective in terms of sideeffects and cost, therefore, other regimens may be used instead of daily conventional dose. ${ }^{15}$

Thus it is important to analyze its risk- benefit ratio at lower dosages. Therefore, present study was conducted to determine efficacy and safety profile of oral isotretinoin (13-Cis-Retinoic Acid) therapy in patients of acne vulgaris.

\section{METHODOLGY}

Present study was carried out among the acne vulgaris cases attending the outpatient department of dermatology, Uttar Pradesh University of Medical Sciences, Saifai, UP (India) during April 2015 to March 2016. 56 patients with grade II to grade IV acne vulgaris as per Pillsbury's scale, within the age group of 14-25 years were included for study. Patients with abnormal baseline investigations, pregnant females, married females desiring to get pregnant or using temporary methods of contraception, lactating female, known hypersensitivity to isotretinoin, patients having family and/or personal history of hyperlipidemia or diabetes, those having drug-induced acne \& concomitant use of other antibiotics such as tetracycline were excluded from study.

Routine laboratory investigations carried out which included CBC, Fasting blood sugars, LFT, Lipid profile. A wash out period of 1 week for those using topical application and 2 weeks for those using systemic drugs for acne is given. The study includes variables like age of onset of acne, duration of lesions, previous therapy \& history of allergy to any product. In all these cases a general and cutaneous examination was carried out and type and distribution and count of acne lesions comedons, inflammatory lesions as well as total lesions were recorded. The lesions were counted by using Leeds technique of Burke and Cunliffe. Oral isotretinoin was started at a dose of $0.5 \mathrm{mg} / \mathrm{kg} /$ day for a total duration of 20 weeks. Patients were scheduled for 3 visits i.e. at the end of 1 st, 2nd \& 5th month after start of treatment. Efficacy was determined by evaluating inflammatory lesions count at baseline and at every visit. ${ }^{16}$ Institutional ethical committee approval was taken prior to the study. Written informed valid consent of the Patients fitting into the criteria was taken.

Table 1: Efficacy of oral Isotretinoin on number of comedons and inflammatory lesions

\begin{tabular}{|c|c|c|c|c|c|c|}
\hline \multirow{2}{*}{$\begin{array}{c}\text { Time } \\
\text { Interval }\end{array}$} & \multicolumn{3}{|c|}{ Comedons } & \multicolumn{3}{|c|}{ Inflammatory Lesion } \\
\hline & Mean & SD & $P$ value & Mean & SD & $P$ value \\
\hline Baseline & 39.19 & 17.28 & $<0.001$ & 32.85 & 16.92 & $<0.001$ \\
\hline 1 month & 27.67 & 15.9 & & 19.78 & 11.67 & \\
\hline 1 Month & 27.67 & 15.69 & $<0.001$ & 19.78 & 11.67 & $<0.001$ \\
\hline 2 month & 20.07 & 13.57 & & 12.65 & 8.47 & \\
\hline 2 month & 20.07 & 13.57 & $<0.001$ & 12.65 & 8.47 & $<0.001$ \\
\hline 5 month & 10.15 & 8.97 & & 5.35 & 4.03 & \\
\hline Baseline & 39.19 & 17.28 & $<0.001$ & 32.85 & 16.92 & $<0.001$ \\
\hline 5 month & 10.15 & 8.97 & & 5.35 & 4.03 & \\
\hline
\end{tabular}

\section{RESULTS}

56 patients Participated in the study. Table shows the efficacy of isotretinoin on comedons and inflammatory lesions, the mean of comedons decreases from baseline 39.19 to 10.15 at the time of last visit i.e. on 5 th month.

As well as inflammatory lesions decreased from 32.85 to 5.35 at the time of last visit at 5 month. These findings were statistically significant $(<0.001)$.

Safety evaluation of the drug was observed with the side effect of the drug during or at the end of the treatment. Dry skin, Dry mouth, Dry eyes, palmo-plantar peeling, exfoliative dermatitis, photosensitivity, facial dermatitis, skin infections, \& Cheilitis were observed. Systematic side effects like Nausea, diarrhea, abdominal pain were observed in 2 patients.

\section{DISCUSSION}

Isotretinoin is quite a useful therapeutic advance in the management of acne. It has been recommended for the treatment of severe nodulocystic acne in the doses of $0.5-2 \mathrm{mg} /$ day. ${ }_{1}{ }^{15,17,18}$ While using this treatment protocol the incidence of side-effects is quite high and requires regular monitoring including a watch on the serum lipid profile. It has been debated whether isotretinoin should be reserved for severe nodulocystic acne only or it can be used for mild and moderate acne also. ${ }^{19}$ To decrease the incidence of side-effects and to make the therapy protocol simpler, the lower dose regimen has been tried by various authors. ${ }^{20-22}$ Most of these studies have found that low-dose and intermittent regimens of isotretinoin are effective in moderate to severe acne with a low incidence and severity of side-effects. 
Oral isotretinoin if used in correct dose, it is very seldom fails to clear acne completely and it effects a permanent cure in large number of cases. ${ }^{23}$

In the present study, 56 patients participated (34 were males $(60.7 \%)$ and 22 were females (39.3\%) and there was no statistical significance in both the groups and thus were comparable. In present study, oral isotretinoin was started at a dose of 0.5 $\mathrm{mg} / \mathrm{kg} /$ day for a total duration of 20 weeks. We included moderate to severe cases of acne, we did not follow the criteria of total accumulated dose schedule of $120 \mathrm{mg} / \mathrm{kg}$ as followed in other studies carried for the more severe forms of acne.

Mandekou -Lefai et al. ${ }^{24}$ in their study "low - dose schema of isotretinoin in acne vulgaris" treated a group of 32 patients of different types and grades of acne vulgaris with oral isotretinoin in dose from $0.15-4 \mathrm{mg} / \mathrm{kg} /$ day. The mean success rate was only $69 \%$. Hermes B et al. ${ }^{25}$ in their study "medium dose isotretinoin for the treatment of acne" treated 94 patients of moderate to severe acne vulgaris with stepwise incremental dose, for a mean duration of 8.3 months, at a mean dose of $34.4 \mathrm{mg}$. In their study oral isotretinoin was administered in initial dose of $10 \mathrm{mg} /$ day with a variable increase according to tolerability, reaching a mean dose $0.43 \mathrm{mg} / \mathrm{kg}$ and reported very good results in $62.8 \%$ and good results in $31.9 \%$ of patients. Chetan $D$ et al. ${ }^{16}$ studied 38 patients and found $50 \%$ decrease in comedons at the end of 2 month from the initiation of treatment. The efficacy of oral isotretinoin on inflammatory lesions showed decreased from baseline 36.13 to 4.87 at the time of last visit at 5 month. Similar findings were reported in present study where we studied 56 patients. Comedons decreases from baseline 39.19 to 10.15 at the time of last visit i.e. on 5 th month. As well as inflammatory lesions decreased from 32.85 to 5.35 at the time of last visit at 5 month. These findings were statistically significant $(<0.001)$.

The total number of patients with side effects were $8(14.3 \%) .5$ $(8.9 \%)$ out of 56 patients showed muco cutaneous side effects which include Dry skin, Dry mouth, Dry eyes and palmo-plantar peeling. $3(5.4 \%)$ patients presented with chelitis. 2 (3.6\%) patients developed mild gastrointestinal side effects including nausea and vomiting. However these mild side effects only required symptomatic treatment instead of discontinuing of treatment. The study concludes that isotretinoin was safe and effective in reducing the acne lesions.

In previous studies, less common adverse effects were seen as benign intracranial hypertension, so therapy must be

stopped if a patient experiences persistent headaches. Isotretinoin can also be associated with a mild to moderate elevation in liver enzymes and in serum lipid indices, especially triglycerides. It is generally well accepted that baseline cholesterol, fasting triglycerides, and liver function tests be done. Follow-up tests are recommended at weeks 4 and $8 .{ }^{26}$

Isotretinoin is a proven teratogen, and its use necessitates adequate contraception during and 6 weeks after therapy, as well as baseline and monthly pregnancy tests. Major malformations occur in $40 \%$ of infants exposed to isotretinoin in the first trimester. It is strongly recommended that patients have 2 negative pregnancy tests before starting isotretinoin and regular monthly pregnancy tests thereafter. ${ }^{27}$

So, it can be concluded that oral isotretinoin is an effective and safe drug in the management of acne producing long-term remission and/or significant improvement in many patients.

\section{REFERENCES}

1. Dreno B, Poli F. Epidemiology of acne. Dermatology 2003:43:1042-8.

2. Kaymak $Y$, Ilter $N$. The effectiveness of intermittent isotretinoin treatment in mild or moderate acne. J Eur Acad Dermatol Venereol 2006;20:1256-60.

3. Aamir Haider, James C. Shaw. Treatment of Acne Vulgaris (clinical review) JAMA, 2004; 292(6); 726-735.

4. Bataille V, Snieder H, MacGregor AJ, Sasieni P, Spector TD. The influence of genetics and environmental factors in the pathogenesis of acne: a twin study of acne in women. J Invest Dermatol. 2002;119:1317-1322.

5. Goulden V, McGeown CH, Cunliffe WJ. The familial risk of adult acne: a comparison between first degree relatives of affected and unaffected individuals. Br J Dermatol. 1999;141:297-300.

6. Cordain L, Lindeberg s, Hurtado M, Hill K, Eaton SB, BrandMiller J. Acne vulgaris: a disease of western civilization. Arch Dermatol. 2002;138:1584-1590.

7. Clark S.M., Goulden V., Finlay A.V. The psychological and social impact of acne: a comparison study using 3 acne study disability questionnaires. Br J Dermatol.1997; 137 suppl. 50:41.

8. Gollinick H., W Cunliffe. Management of acne. JAAD 2003; 49 (1): S15.

9. Zouboulis CC, Piquero, Martin. Update and future of systemic acne treatment. Dermatolgy 2003; 206 (1): 37-53.

10. Harper JC, Thibutot DM. Pathogenesis of acne: Recent research advances. Adv Dermatol 2003;19:1-10.

11. Olson $\mathrm{J} A$ : The biological role of vitamin $A$ in maintaining epithelial tissues 1972. Isr J Med Sci 8:1170-1178.

12. Holmes RL, Williams M, Cunliffe WJ: Pilo-sebaceous duct obstruction and acne. Br J Dermatol 87:327-332, 1972

13. Michaelsson $G$. Vahlquist $A$, Juhlin L: Serum zinc and retinolbinding protein in acne. $\mathrm{Br} J$ Dermatol 96:283-286. 1977

14. Rollman 0 , Vahlquist $A$ : Vitamin $A$ in skin and serum: studies of ichthyosis vulgaris, lichen planus, acne and atopic dermatitis. $\mathrm{Br}$ J Dermatol 113:405- 413, 1985

15. Cunliffe W, Gollnick H. Acne. In: Arndt KA, LeBoit PE, Robinson JK, Wintroub BU, editors. Cutaneous Medicine and Surgery. Philadelphia, Pa: WB Saunders Co; 1996. p. 461-80.

16. Chetan D. Rajput, D. G. Saphale. Study of Efficacy, Safety \& Tolerability of Oral Isotretinion in patients of moderate to severe Acne Vulgaris. Journal of Evolution of Medical and Dental Sciences 2014; 3(55), October 23; Page: 12622-12626, DOI: 10.14260/jemds/2014/3671

17. Akman A, Durusoy C, Senturk M, Koc CK, Soyturk D, Alpossy E. Treatment of acne with intermittent and conventional isotretinoin: A randomised controlled multicenter study. Arch Dermatol Res 2007;299:467-73.

18. Culniffe WJ, van de Kerkhof PC, Caputo R, Cavicchini S, Cooper A, Fyrand OL, et al. Roaccutane treatment guidelines: results of an international survey. Dermatology 1997;194:351-7.

19. Bellosta M, Vignini M, Miori L, Rabbiosi G. Low-dose isotretinoin in severe acne. Int J Tissue React 1987;9:443-6.

20. Geissler SE, Michelsen S, Plewig G. Very low dose isotretinoin is effective in controlling seborrhoea. J Dtsch Dermatol Ges 2003;1:952-8.

21. Amichai B. Long term mini doses of isotretinoin in the treatment of relapsing acne. J Dermatol 2003;30:572.

22. Sardana K, Garg V K, Sehgal V N, Mahajan S, Bhushan P. 
Efficacy of fixed low-dose isotretinoin (20 mg, alternate days) with topical clindamycin gel in moderately severe acne vulgaris. J Eur Acad Dermatol Venereol 2009;23:556-60.

23. Munro-Ashman D. Acne vulgaris in a public school. Trans St John's hosp Dermatol Soc 1963; 49: 144-8.

24. Mansekou-Lefaki. Low dose schema of isotretinoin in acne vulgaris. Department of Dermatology, Aristolteles University of Thssalonki. Greece.

25. Hermes B, Praetel C, Henz BM.Medium dose isotretinoin for the treatment of acne. J Eur Acad Dermatol Venereol 1998; 11 (2): 117-21.

26. Barth JH, MacDonald-Hull SP, Mark J, et al. Isotretinoin therapy for acne vulgaris: a reevaluation of the need for measurements of plasma lipids and liver function tests. $\mathrm{Br} J$ Dermatol. 1993; 129:704-707.

27. Koren G, Avner M, Shear N. Generic isotretinoin: a new risk for unborn children. CMAJ. 2004; 170:1567-1568.

\section{Source of Support: Nil.}

Conflict of Interest: None Declared.

Copyright: (c) the author(s) and publisher. IJMRP is an official publication of Ibn Sina Academy of Medieval Medicine \& Sciences, registered in 2001 under Indian Trusts Act, 1882.

This is an open access article distributed under the terms of the Creative Commons Attribution Non-commercial License, which permits unrestricted non-commercial use, distribution, and reproduction in any medium, provided the original work is properly cited.

Cite this article as: Sankalp Awasthi, Nek Ram Baghel, Sweta Kumari, Pankaj Rao, Saurabh Agrawal, R S Rajpoot. Study of Oral Isotretinoin (13-Cis-Retinoic Acid) Therapy in Patients of Acne Vulgaris. Int J Med Res Prof. 2016; 2(4):151-54. 